\title{
The Role and Function of Universities in the Globalization of the Development of International Higher Education
}

\author{
Dr. Irine Bakhtadza ${ }^{1}$, Taona Talikedze ${ }^{2}$ \\ Affiliated Professor at International Black Sea University, Faculty of Social Sciences, Education \& Humanities, David Aghmashenebeli \\ Alley 13 km, N2, 0131 Tbilisi, Georgia
}

${ }^{2} \mathrm{PhD}-\mathrm{c}$ at International Black Sea University, Faculty of Social Sciences, Education \& Humanities, David Aghmashenebeli Alley 13 km, N2, 0131 Tbilisi, Georgia

\begin{abstract}
The goal of the article is to highlight the role and the functions of the modern university campuses in development of $21^{\text {st }}$ century educated multicultural society based on shared moral, ethical and human values. Globalization of American campuses has become an international trend which bears some unique features and is shared by many countries throughout the world. Globalization of knowledge and of higher education necessitates creation of more universities in different parts of the world. The article presents some basic characteristics of international level global university campuses which laid the foundation of recently established the Kutaisi International University in the city of Kutaisi, Georgia. The universities of Georgia have been hosting international students since Soviet period, but now the country faces the necessity of creating an international type university campus the aim of which is to generate intellectual capital and become a hub for international students' education. The article provides survey analysis of the international students' responses who study at Georgian Universities; also, the evaluation of the interviews with Georgian educators and international students' office managers is presented who share their opinion about international students at Georgian universities, their attitudes, problems and perspectives.
\end{abstract}

Keywords: globalization of education, US campus-based universities, Knowledge-based production, the Kutaisi International University, Georgian higher education, IBSU

\section{Introduction}

Each new century brings new challenges and demands in every sphere and the $21^{\mathrm{St}}$ century is not an exception as well. Today, a rapid pace of globalization necessitates dealing with multiple issues; we all witness how our society is becoming diverse regarding race, ethnicity, and nationality. Accelerated process of communication between the countries has established new social and cultural reality. The role of the modern university campus is especially important in development of $21^{\text {st }}$ century multicultural society based on shared moral, ethical and human values. The Universities and campuses, which are the main engines of producing knowledge, contribute a lot to generate more tolerant society advanced beyond narrow personal or national goals to address vital problems of the mankind.

The article presents rationale for foundation of a new, international, campus-based -Kutaisi International University in Western Georgia which aims to create intellectual capital and become a hub of science and technologies. We no longer live in our local world dominated by local systems, for example, local education, local economy, and local political or social life, rather it is a world of shared scientific achievements which have become a distinguished characteristic of globalization.

Which distinctive features of global universities should new Georgian campus-based universities reflect in this tightly interdependent world? "One of the paradoxes of Globalization is that difference is becoming increasingly normative. Globalization and massive migrations are changing the ways we experience national identities or cultural belonging" (Marcelo M. Suarez-Orozso and Desiree Baolian Qin- Hilliard, 2004, p. 3). Going through this labyrinth and facing the challenges is only possible with the help of instrumental knowledge. "Knowledge is a social memory, a connection to the past and it is social hope, an investment in the future. The ability to create knowledge and put it into use is the adaptive characteristic of humans. It is how we reproduce ourselves as social beings and how we change - how we keep our feet on the ground and our heads in the clouds" (Menand, 2010). But what type of education do we actually need to interact with global world, and what skills are so demanding to get involved and keep up with the pace of current global processes? It is really important that all universities of different countries should do their best to respond to new challenges and to empower their students with skills and knowledge useful in today's world. "An education for globalization should nurture the higher-order cognitive and interpersonal skills required for problem finding, problem solving, articulating arguments, and deploying verifiable facts or artifacts to substantiate claims. These skills should be required in order to fully engage the large world and master its greatest challenges, transforming it for the betterment of humanity - regardless of national origin or cultural upbringing"(Marcelo M. Suarez-Orozso and Desiree Baolian Qin- Hilliard, 2004, p. 6).

\section{Methodology and Approach}

We have reviewed the existing literature round the problem, using different sources, online resources, books and articles. In addition, some primary data have been obtained with the 
help of qualitative interviews and a survey. The study of IBSU archives and other official documentations and sites created for Kutaisi International University; also data obtained from GeoStat and GAM news made it possible to provide an analysis based on reliable primary data.

The article refers to Duderstard and Wildarsky refer to some new roles for the $21^{\text {St }}$ century global university which are reshaping the world. A detailed study of multicultural services and programs was necessary to make a factualbased analysis. Some important facts from the history of higher education in Georgia are applied in the article to explain that the foundation of new international campusbased university has had deep roots in the history of Georgia.

\section{American University - A Mini Model of a Multicultural Society}

The knowledge of intercultural communication skills has become essential to interact in this globalized society, and the university campuses emerged as one of the proven means to realize this necessity. American university of the $21^{\text {st }}$ century is renowned for its multinational and multicultural campuses that bring together students of diverse cultural, ethnical, or racial background. It is a truly international institution which not only reflects a strong international character of its students, faculty, and academic programs, but also stands at the center of a world system of generating and sharing knowledge (DUDERSTADT, winter 2000). Today higher education has become more marketoriented; to become competitive in the global market, universities are largely focused on producing intellectual capital andon converting education into commercial product. Sprawling global campuses across the world responds and reflects the process of globalization. But who are the actors and beneficiaries of this process? Firstly, those are international students, the staff, lecturers, professors who turn those institutions into a global space where the students interact with diverse cultures, values, moral and ethical norms. Global campuses which incorporate students' unions, clubs and associations offer great opportunityto their students to share knowledge, experience and ideas, and conduct collaborative research. Intercultural skills student acquire on campuses help them to be shaped as global citizens to successfully integrate, work and live in a multicultural environment.

Year by year, the number of international students in American Universities is increasing; by 2025, the number of international students could reach eight millions, says Hans de Wit, director of the Center for International Higher Education, Boston College in the US (Mitchell, 2016). The demand for global campuses is increasing every year and the reason is that campus provides the students with broad knowledge beyond academic programs and offers a rich and diverse campus life; it helps students to get close to each other, to get engaged actively in social, cultural or sport life by participating in different cultural, social and sport events. Most American universities offer their students a rich campus life, multiple extracurricular activities which meet the students' diverse interest. For example, the Office of Multicultural Services and Programs at the University of
Georgia, US, focuses on creating an inclusive campus environment to engage its international students into active University life.There are 12 multicultural students' organization at UGA: such as Asian American Student Association (AASA), Hispanic Student Association (HSA), etc. (Multicultural Services and Programs, n.d.).The existence of so many multicultural clubs at universities reflects how American universities promote understanding and tolerance among their students who have brought with them different beliefs, principles and experience. Involvement in these clubs enables students to acquire multicultural skills and get acquainted with foreign cultures. In addition, there are students' self-government, sport clubs, art, academic or other professional organizations. The members of Students' Government are elected by the students and is "the official voice" of students to represent the ideas and concerns of their fellow students to the University administration. Sport activities are popular extracurricular activities of American campuses that promote healthy life-style. For those who are interested in media, UGA offers its students Media clubs which consist of print, television, and radio venues to engage them into different political and socio-cultural issues. All campus based clubs and associations at UGA go far beyond the academic life and help its students to get broader education, raise awareness around global issues, acquire intercultural skills, and identify their interests and aptitudes.

The history of American Campus life goes back to the $18^{\text {th }}$ century, but the foundation of modern campus structure, its content and environment was predominantly formed in the 1960s. According to 1993 article by Alexander Astin, campus extracurricular activities have positive effect on students' emotional, intellectual, social, and inter-personal development. Furthermore, involvement in diverse activities help the students to better understand their own abilities and link academic knowledge with practical experience (TENHOUSE, n.d.). According to Ernest T. Pascarella and Patrick T. Terenzini's 1991 research, extracurricular involvement has a positive impact on educational objectives. Students who are actively engaged are more likely to have higher educational ambitions than uninvolved students (TENHOUSE, n.d.).

\section{Globalization of universities - Academic free trade}

Today, it is really difficult to find a university that is not affected by the world ongoing process of globalization. Universities around the world try to keep up with new demands and challenges by establishing world-class universities in their countries to keep more students home and prevent brain drain overseas. The worldwide competition for human talent reveals an undeniable necessity to produce more educated people, which mean more ideas that lead to strengthen increasingly knowledgebased economies and bring benefit for many countries.

Rapid access to world information has made it possible to change the timeworn academic system into a modern global academic organism. Advancement of new technologies laid foundation for new teaching-learning approaches and distance education has become widely accepted practice. 
Technology has made it possible to exchange knowledge and experience accumulated by different nations and create moral and social basis for global citizenship.

Globalization has brought a new kind of free trade - that is a free trade in minds. Since the higher education has become a tradable product, drawing students into international campuses from around the world is a beginning of a new process. In this worldwide marketplace, more and more people regardless their ethnic, racial or cultural belonging will have a chance to trade their knowledge and experience based on what they have achieved rather than who they are. It is the same kind of meritocracy that emerged in the United States when elite universities began talent-based admissions. Currently, Universities tend to compete ever more fiercely for the best minds, the trend toward a world in which talent can rise and reach its greatest potential seems distinctive (Wildavsky, 2010).

Most countries worldwide experience the brain drain when countries' most promising citizens leave home country and go abroad to get better education and high payable job. One good example of which is massive migration of scientists from post-soviet countries, including Georgia, which by the time of the collapse of Soviet system, had had more than seventy scientific- research institutions. This trend still continues, as number of Georgian students get higher education at American universities and upon completion find jobs and stay in the US. But unlike past years, many of those students who get education in the US, return back home and apply their knowledge to contribute to the welfare of the country. This is called "brain circulation"; therefore, global university movement has gone further: from brain drain to brain circulation to what might be called brain growth. As academic free trade has become more important than any kinds of trade, many countries try to make significant investments in education, compete to nurture human capital to produce more educated people that is the key to sustain the knowledge economy and advance global prosperity (Wildavsky, 2010). Since 1950s, the United States has become an incomparable magnet for students and professors from around the world and held most popular study destinations in the educational marketplace. But for last decades, its market share is slowly being eroded by stepped-up competition from overseas universities. Some of the renamed and very popular Western universities are actively involved in the educational world market by establishing satellite campuses in Asia and in the Middle East. They are teaming up with the overseas universities to forge strategic alliances that offer scholarly and marketing advantages to both sides. In the rapid pace of globalization, most countries are working not only to send students to the United States, or to host "branch campuses" on their own soil, but to build world-class universities of their own (Wildavsky, 2010).

\section{Changes in higher education in Georgia and establishment of new international Campus-based University}

Building world-class universities have become one of the top priorities for Georgia as well. Georgian system of education, which passed through a number of groundbreaking reforms since 2000, is actively engaged in global academic practices. Georgia joined the Bologna Process in 2005, since then the country has greatly shaped its higher education system according to the Bologna Process guidelines. Significant changes and progress have been made in the last years in internationalization aspects (SPHERE, n.d.). The National Center for Educational Quality Enhancement, which is responsible for improving the quality of education in the country,is working hard to get involved in the international academic network and cooperate with international institutions. In 2014, the National Center for Educational Quality Enhancement (NCEQE) gained an affiliate status of the European Association for Quality Assurance in Higher Education (ENQA). In 2018 NCEQE applied to the World Federation of Medical Education (WFME) and has already received the recognition status from WFME the same year. NCEQE is the first quality enhancement agency in Europe which received the status from WFME. The Minister of Education and science of Georgia has launched a program- Study in Georgia aiming to promote internationalization, mobility and attractiveness of international students. The government of Georgia allocates the wide-scale investments in the infrastructure for scientific researches and aims to increase the funding.

The number of international students has increased especially for the last years. In 2018-2019 A/Y, 12,200 foreign students studied in Georgia, which is $21.4 \%$ more than it was in the previous year (JAMnews, 2019).Georgian universities as a part of global academic space work hard to offer international students high academic level and up-todate infrastructure. The language of instruction at Georgian Universities is Georgian, but the academic programs for international students in many universities, such as Javakhishvili State University, Medical State University in Tbilisi, are designed and delivered in English. International Black Sea University (IBSU), founded in 1995 in Tbilisi, was the first higher education institution with Englishlanguage based academic programs and campus life, which was very close to American model. European and American exchange academic programs give opportunity to the staff and students to advance their academic knowledge up to international level. Today, many Georgian professors deliver lectures in English language, also there are foreign professors and scholars in Georgian universities who share their experience to their colleagues and students. In the process of globalization of higher education, Georgia as a part of world education system is striving for transforming Georgia into a regional economic hub (SPHERE, n.d.).

Georgian higher education involvement in the global educational network requires establishing campus- based university where students will be able to live on campuses and at the same time will enjoy rich and resourceful campus life like it is in American universities. Yet, some Georgian universities are already actively involved in the internationalizing process. To achieve this goal, the universities intensively work with partner universities around the world and are involved in Erasmus + and other exchange programs. Also, Georgian universities tend to 
become more multicultural as the number of students is increasing annually.

Georgia has rich century-old traditions of higher education. The first higher education institution was founded in the $4^{\text {th }}$ c. A.D.in Phazisi- West Georgia, in which Georgian, Greek and Roman students received higher education; the tradition also continued in the $10^{\text {th }}-12^{\text {th }}$ centuries when the centers for scholastic education were founded by Georgian scholars in Georgia, Asia and Eastern Europe. Historical roots of Georgian higher education, the reforms which supported integration of Georgian university education into European system, and favorable climate and cultural environment create objective basis to consider that Georgia has real chances to develop a global campus-based university which will meet all demands of international society and find its place among world-class universities. A modern campus life comprises a wide range of extracurricular activities; the students' active engagement in scientific and social problems, association with global environmental issues and their intercultural communication skills help them to become a member of world knowledgeable society. The model of a campus based research- study university is still in the process of development in Georgia.

International Black Sea University reflects the process of globalization and internationalization of higher education in Georgia. The University is based on ideals which are common for the universities of democratic countries: equity, equality, competitive quality of education, high moral and ethical values; also, it promotes technological advancement and science development, and supports active students' life on the campus, financing the activity of the clubs, and associations. It has a memorandum of understanding with more than 50 institutions around the world. IBSU is also involved in Erasmus+ and $\boldsymbol{D A A D}$ projects. The university hosts 150 international students from different countries; currently, it has five faculties and 37 accredited academic programs at three levels of education: BA, MA and PhD. The Number of its students has increased from 19 in 1995, to 2152 in 2019. The language of instruction is English. Moreover, the university invites foreign lecturers and professors, holds international level conferences and publishes scientific journals. Therefore, IBSU is a good example how a small university can become a part of global education (Bakhtadze, 2019).

One of the impressive projects that demonstrate the rapid pace of Georgian educational system to get engaged in the globalization of Higher Education is the foundation of the Kutaisi International University (KIU), located in Kutaisi, West Georgia which was launched with the support of International Charity Foundation "Cartu" (The Cartu Foundation). The Importance of the University is essential as it will be an international hub of education, science and technology in the region. A new University is planned to create English-language based academic programs and attract considerable number of international students. The first wave of students will be admitted KIU in September 2020, and will offer its students three academic programs: Management, Mathematics and Computer Science. Academic programs are developed together with the international partners, such as the Technical University of
Munich (TUM) and the Technical University of Munich International (TUM International). There are some other aspects that make this university really unique and important for our country; e.g. it aims to become a research and study University; establishing a Hadron Therapy Center first. This Research Center will offer its facilities for the scientific researches in particle physics, radiation physics and biophysics, as well as support operations of the Proton Therapy Center, coupled with the faculty of Medicine at KIU. In addition to rich and innovative academic life at the university, the Kutaisi International University will offer students modern facilities and infrastructure that will bean international level global campus. The campus is located in the environmentally clean area, which will be equipped with modern state-of- the-art labs, student facilities, libraries and an interactive learning management system. The Kutaisi international University is the one that really encompasses all aspects and features reflecting how international level campus-based university is developing in our country to meet the challenges of globalization process (UNIVERSITY, n.d.).

According to Forbes, Georgia has one of the lowest indicators for students living in residence -with only $2 \%$ (Kvintradze, 2018).Consequently, campus-based university has not yet reached international standards. In addition, there are some student clubs and organizations on Georgian university campuses, but still students are not fully engaged in it. Most students are not even members of any campus clubs or organizations that serve their engagement in modern cultural or social processes. So, from this point, active campus life which is a part of students' social and cultural development will grow with the establishment of KIU which will host increased number of international students and offer interesting campus life.

A number of Personal interviews have been conducted relating to perspectives of campus-based university in Georgia. One of the respondents David Gegechkori, the Head of International Relations and Development Office, Akaki Tsereteli State University, answered our questions.

David Gegechkori:" Founded in 1930, the University has gained its recognition as a result of staff training, high quality scientific potential and close cooperation with scientific institutes of advanced countries. The first international students at Akaki Tsereteli State University were from Turkey, enrolled in 1998. Today the university has 480 international students and has three Englishlanguage programs: Medicine, MA program -Leadership and Management in Higher Education and Pharmacy. "As for the university campus" Mr. Gegechkori said "Our country is really ready to develop an international level campus-based university. There are some universities that have made their own niche which distinguishes them. For example, Tbilisi State Medical University (TSMU) is the main center of higher medical education. Another example is Batumi International University (BAU) which is a leader University in Georgia equipped with latest technologies. It is a university within the BAU Global Network which is made up of 8 Universities, 16 information center and 4 language schools spread in 9 countries over 4 continents. Moreover, it has American model of educational programs that fully 
corresponds to international standards. Thus, Universities in Georgia are ready to adequately respond to global higher education demands and host international students." A number of semi-formal interviews have been conducted by us to find out the reasons why international students chose to continue studies at ATSU. The number of respondents was 12, and they came from Turkey, India and Egypt. The majority of the respondents answered that the main reason for choosing the university was high quality academic programs, e.g. MBBS. Also, they are satisfied with university administration work and management. Some respondents talked about favorable climate and good quality water and food available for affordable price in Georgia; also an affordable tuition fee is one of the most important reasons for choosing the university. As for extracurricular activities, the respondents answered that they have no idea if there are any clubs or associations. Some said that those clubs don't involve foreign students.

\section{Conclusion}

Georgian higher education is striving to continue its centuryold traditions of higher education, attract economic, financial and human capital to build a world-class university of its own. To respond to international standards, some new type of campus-based universities is being constructed in Georgia which by offering international students high quality education will soon join global education network.KIU will serve multiple goals: increase brain circulation, advance new technologies and science, create healthy environment for raising new generation in Georgia with intercultural communication skills able to trade their knowledge worldwide. New Georgian universities equipped with up-to-date technologies and labs and campus which will provide its students with rich extracurricular activities and multicultural environment will hopefully become a hub of international higher education and cross-cultural understanding, and finally emerge as a global trend. Georgian higher education deserves to become a worthy member of international knowledge and science-generating higher education institutions.

\section{References}

[1] Bakhtadze, I. (2019). American University Campus Reflection of Globalization Process. International Black Sea University Scientific Journal in Humanities, 8(1), 28-30.

[2] DUDERSTADT, J. J. (winter 2000). New Roles for the 21st-Century University. Retrieved March 9, 2020, from Issues in Science and Technology: https://issues.org/duderstadt/

[3] JAMnews. (2019, March 11). Education in Georgia in numbers - the latest data from GeoStat. Retrieved March 15, 2020, from JAMnews: https://jamnews.net/education-in-georgia-in-numbers-the-latestdata-from-geostat/

[4] Kvintradze, N. (2018, November 13). What is the difference between Georgian and European Students in Higher Education? Retrieved March 16, 2020, from Forbes Georgia: https://forbes.ge/news/5172/What-isthe-difference-between-Georgian-and-European-

Students-in-Higher-Education
[5] Marcelo M. Suarez-Orozso and Desiree Baolian QinHilliard. (2004). GLOBALIZATION CULTURE AND EDUCATION IN THE NEEW MILLENNIUM. Berkeley, Los Angeles ,London: University of California Press.

[6] Menand, L. (2010). The Marketplace of Ideas:Reforms and Resistance in the American University. New York. London: W.W.Norton\& Company.

[7] Mitchell, N. (2016, February 3). Universities compete by teaching in English. Retrieved November 10, 2019, from BBC News: https://www.bbc.com/news/business35429233

[8] Multicultural Services and Programs. (n.d.). Retrieved March 14, 2020, from The University of Georgia: https://msp.uga.edu/content_page/vision-and-mission

[9] SPHERE. (n.d.). Higher education in Georgia. Retrieved March 15, 2020, from SPHERE :Support and Promotion For Higheer Education Reform Experts: https://supporthere.org/page/higher-education-georgia

[10] TENHOUSE, A. M. (n.d.). College Extracurricular Activities:Impact on Students, Types of Extracurricular Activities. Retrieved March 14, 2020, from https://education.stateuniversity.com/pages/1855/Colleg e-Extracurricular-Activities.html

[11] UNIVERSITY, K. I. (n.d.). About KIU. Retrieved April 2, 2020, from KUTAISI INTERNATIONAL UNIVERSITY: https://kiu.edu.ge/index.php?m=186

[12] Wildavsky, B. (2010). The Great Brain Race :How Global Universities Are Reshaping the World. Princeton, New Jersey: Princeton University Press Princeton \& Oxford 